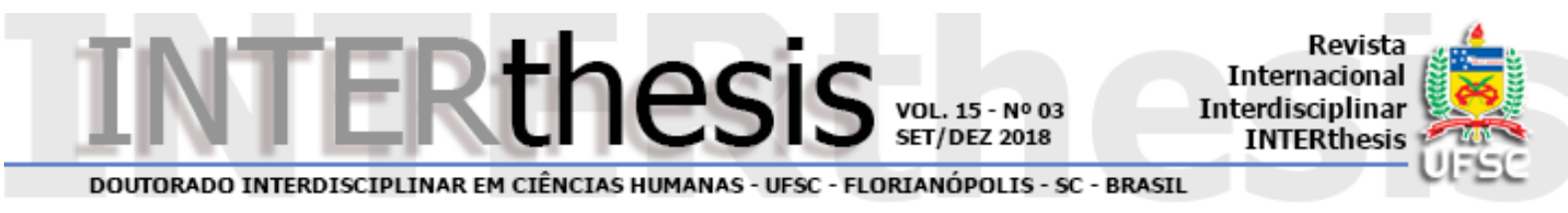

\title{
A MULHER NEGRA PROFESSORA E SEUS LUGARES DE PERTENCIMENTO
}

\section{Resumo:}

Claudia Moreira Costa ${ }^{1}$ Maria de Fátima Di Gregorio²

Este artigo é o resultado de uma investigação realizada com um grupo de mulheres negras professoras de um programa de formação continuada, promovido pelo Órgão de Educação e Relações Étnicas (ODEERE), da Universidade Estadual do Sudoeste da Bahia (UESB). Focaliza a construção dos saberes profissionais, privilegiando as identidades de gênero e étnica. Para tanto, objetivou-se investigar como professoras negras egressas do Curso de Extensão em Educação e Culturas Afro-brasileiras do ODEERE têm articulado as questões de gênero e etnicidade aos seus saberes profissionais, buscando compreender os percursos e dilemas desse processo. Nesse sentido, analisou-se as categorias gênero, identidade étnica e saberes profissionais. Trata-se de uma pesquisa empírica, de natureza qualitativa, ancorada na História Oral. Os achados apresentam elementos para pensar os sentidos atribuídos ao curso de formação continuada na percepção, reconhecimento e/ou embasamento teórico para a identidade de gênero e afirmação do pertencimento étnico, assim como a mobilização de saberes profissionais para lidarem com questões dessa natureza em suas práxis.

Palavras-chave: Professoras Negras. Gênero. Identidade Étnica. Saberes Profissionais.

\section{INTRODUÇÃO}

Este artigo resulta de uma investigação realizada com um grupo de mulheres negras professoras egressas de um programa de formação continuada, promovido pelo Órgão de Educação e Relações Étnicas (ODEERE), da Universidade Estadual do Sudoeste da Bahia (UESB), campus de Jequié, tendo como objetivo investigar como estas professoras têm articulado as questões de gênero e etnicidade aos seus saberes profissionais, tomando como parâmetro o ingresso no Curso de Extensão

\footnotetext{
${ }_{1}$ Mestre em Relações Étnicas e Contemporaneidade na Universidade Estadual do Sudoeste da Bahia, Jequié, BA. Pesquisadora do Grupo de Estudos Hermenêuticos sobre Família, Territórios, Identidades e Memórias. Professora da rede municipal de ensino de Jaguaquara, BA, Brasil E-mail: cmclaudia3@gmail.com

2 Doutora em Família na Sociedade Contemporânea na Universidade Católica de Salvador. Coordenadora do Grupo de Estudos Hermenêuticos sobre Família, Territórios, Identidades e Memórias. Professora de História da Educação na Universidade Estadual do Sudoeste da Bahia Campus Jequié e do Mestrado em Relações Étnicas e Contemporaneidade na Universidade do Sudoeste da Bahia, Jequié, BA, Brasil E-mail: $\underline{\text { digregorio@hotmail.com }}$
} 
em Educação e Culturas Afro-Brasileiras. As atividades desse órgão fomentam a pesquisa nas áreas das relações étnicas, diversidade sexual e gênero, favorecendo a inserção de professores/as da Educação Básica a estarem em contato com as questões e conteúdos relacionados às temáticas.

As tramas históricas, às quais fazem parte do desenvolvimento profissional de professoras-negras, evidenciam as questões de gênero e pertencimento étnico como fontes de identidades que trazem à tona vivências, questionando posturas e afirmando lugares. Destarte, a carreira do magistério permite às mulheres o acesso a um espaço público anteriormente frequentado por homens, mas, dentro dos moldes patriarcais, trazendo referências ao trabalho praticado por elas no lar, reforçando/naturalizando a docência como uma profissão dotada de estereótipos ligados aos "papéis femininos" construídos socialmente, como cuidado, amor, sensibilidade.

Importa, ainda, considerar que as mulheres negras foram as últimas a ingressarem no magistério, por conta de alguns marcadores, dentre eles os de gênero e etnia e esta inserção, de acordo com Gomes (1995), rompeu com o imaginário social de incapacidade intelectual dos negros; no entanto, a partir da inserção na carreira docente, tiveram que lidar constantemente com o desafio de lidar com preconceitos e mostrar-se competente.

Nesse sentido, a presença da mulher-negra na carreira docente traz à tona a necessidade de compreensão do contexto sócio-histórico-cultural como referencial de seu processo identitário. No caso deste estudo, tais processos importam especificamente no que tange à experiência social construída por essas professoras a respeito de gênero e identidade étnica em intersecção com suas experiências como professoras.

A perspectiva de gênero traz reflexões acerca do processo histórico engendrado no magistério, evidenciando as contingências, descontinuidades, permanências e rupturas. À luz das contribuições Joan Scott (1995), Guacira Louro (1997; 2008), Cláudia Vianna (2002; 2013), Nilma Lino Gomes (1995) e Heleieth Saffioti (1976), são apresentados elementos que contribuem para pensar como se produziu a mulher professora, ao mesmo tempo em que contribui para pensar a posicionalidade da mulher negra nesse processo.

A identidade étnica é tratada recorrendo ao enfoque presente nos estudos de Fredrik Barth (2011), Poutignat e Streiff-Fenart (2011) e Carneiro da Cunha (2009), 
trazendo como perspectiva a construção realizada no processo de transformação e interação dos grupos que se reflete sobre a individualidade de cada professora considerando as vivências de atribuição (de pessoas para com elas) e de autoatribuição (delas em relação a elas próprias), pois é na diferenciação que se contrapõe a singularidade e o sentimento de pertença se institui.

Quanto à explicitação do conceito de identidades profissionais, enfatizam-se os estudos de Maurice Tardif (2014) e António Nóvoa (1997), nos quais a atividade docente carrega as marcas da trajetória de vida, do lugar de atuação profissional e da experiência com sua própria atividade. Diante dessa abordagem, considera-se que os saberes docentes têm natureza social e implicam um processo de aprendizagem e de formação.

\section{CAMINHOS METODOLÓGICOS}

Dada às especificidades do objeto de pesquisa, a metodologia está ancorada na História Oral a qual valoriza as subjetividades de quem participa da pesquisa. Nessa perspectiva, ao evidenciar suas vozes, no processo de construção dos saberes e as identidades profissionais, podem ser revelados os significados, as escolhas, os desafios, as trajetórias, as experiências pessoais e a atuação docente.

A amostra constituiu-se de quatro professoras, autodeclaradas negras, que participaram do Curso de Extensão em Educação e Culturas Afro-brasileiras do ODEERE, sendo que a seleção das colaboradoras ocorreu a partir da organização em rede, conforme orientam os estudos de Meihy e Holanda (2013). O trabalho de campo foi efetivado em três etapas: aplicação de um questionário de identificação, entrevista semiestruturada e análise dos relatos das professoras. Vale ressaltar que, ao utilizar as falas das professoras - narrando histórias singulares, diferentes, próprias de cada trajetória -, pela questão do anonimato necessário à pesquisa, foram atribuídos nomes africanos com o intuito de preservar suas identidades. Para tanto, foram utilizados os codinomes: Ayo, Dandara, Zulai e Zunduri.

\section{MULHERES NEGRAS PROFESSORAS: SENTIDOS PRODUZIDOS EM SEUS SABERES PROFISSIONAIS}

Os saberes profissionais são plurais e trazem no centro de suas reflexões a articulação dos aspectos sociais e individuais dos saberes referendados pela história 
da sociedade, de sua cultura, poderes e contradições. À luz dos estudos de Tardif (2014) e Nóvoa (1992), compreende-se que esses saberes estão relacionados com os lugares nos quais as professoras participantes dessa pesquisa atuam, estudam, trabalham e vivenciam, os mesmos passam pelas memórias dessas profissionais em diferentes modos de subjetivação. Nessa ótica, a valorização das individualidades e história de vida possibilitam compreender como percebem a construção de suas identidades docentes.

A presença da mulher negra na carreira do magistério conduz tratar, dentre as múltiplas questões que as diferenciam, sobre os enfoques de gênero e etnicidade como operações de classificação cultural, os quais têm ordenado pensamentos e ações sociais. Nessa perspectiva, pensar o desenvolvimento de mulheres-negrasprofessoras incide no intercâmbio da compreensão de si mesmas e do contexto de trabalho onde estão inseridas.

Partindo do pressuposto de que a identidade constrói-se historicamente diferindo de cultura para cultura e com base nos estudos de Souza (1983) sobre ser negro no Brasil, considera-se que ser negra é assumir-se enquanto tal apropriandose do sentimento de identidade e pertencimento. De acordo com a autora, não se nasce negra, "torna-se negra" e esse processo requer:

[...] tomar consciência do processo ideológico que, através de um discurso
mítico acerca de si, engendra uma estrutura de desconhecimento que o
aprisiona numa imagem alienada, na qual se reconhece. Ser negro é tomar
posse desta consciência e criar uma nova consciência que reassegure o
respeito às diferenças e que reafirme uma dignidade alheia a qualquer nível
de exploração (SOUZA, 1983, p. 77 ).

Tomar posse dessa consciência perpassa por processos de desconstrução, ancorados em referenciais presentes no conjunto da cultura brasileira sobre o ser negro/a, e buscar nas dimensões pessoal, histórico-cultural a percepção do seu grupo de pertença. Considerando a cultura enquanto produção humana, composta de um universo simbólico - compreendidos, aqui, na perspectiva de Laraia (1996) cuja rede de relações e significações lançam os sujeitos em um movimento de interpretações, a autoafirmação sucede através de sistemas simbólicos de representação. Tais sistemas adquirem significado no processo de construção da identidade étnica e de gênero, posto que revelam-se como espaços de produção de saberes, sentidos e interações marcadas pelas diferenças (SILVA, 2014).

Diante dessas prerrogativas, o enquadramento subjetivo das histórias de vida das quatro professoras colaboradoras dessa pesquisa desvelaram contextos sociais 
responsáveis por suas identificações, intenções e motivos a partir dos quais são atribuídos sentidos aos seus processos de desenvolvimento profissional.

Como o foco de interesse desse estudo é o curso em Educação e Culturas Afro-brasileiras, promovido pelo ODEERE, destaca-se os sentidos atribuídos ao curso na percepção, reconhecimento e embasamento teórico para mobilização de saberes profissionais que conduzem o entendimento de gênero e etnicidade como elementos significativos no processo de construção dos saberes profissionais de mulheres-negras-professoras.

Mesmo considerando que os saberes profissionais são plurais e estão relacionados aos aspectos sociais e individuais, considera-se pertinente traçar um breve perfil de cada colaboradora desse estudo, abordando apenas os saberes profissionais construídos pelas instituições formadoras: inicial e continuada. Os demais saberes serão abordados ao longo do texto.

Dandara se autodeclara negra e há 35 anos atua como professora na educação básica. Cursou graduação, tem especialização e participou de três cursos no ODEERE. Sua participação nos cursos promovidos pelo órgão foi motivada pela curiosidade e durante os estudos se sentiu provocada e ao mesmo tempo chocada com o conteúdo abordado. Após o curso, seus saberes profissionais ganharam reforço de atividades que valorizam as diferenças por considerar que todos os grupos étnicos têm "os seus conhecimentos e os seus saberes". E assim, considera que o acesso ao curso the propiciou reflexões e, consequentemente, pode descolonizar seu pensamento, fruto da educação "eurocêntrica" que teve em seu processo de formação.

Zulai se autodeclara negra e há 18 anos atua como professora na educação básica. Cursou uma graduação, duas especializações e participou do curso de Extensão em Educação e Culturas Afro-brasileiras, no ODEERE. O que moveu seu interesse em participar dessa formação foi a necessidade em atender a Lei 10.639/2003 e seus desdobramentos pedagógicos. Após o curso, utilizou os conhecimentos adquiridos através dos aportes teóricos e experiências para realizar algumas atividades. Para Zulai, essas atividades contribuíram para estimular 0 respeito "as diferenças valorizando cada um dentro de sua formação cultural".

Ayo se autodeclara negra e há 18 anos atua como professora da educação básica. Fez duas graduações, uma especialização e participou de duas formações no ODEERE. Inscreveu-se no Curso de Extensão em Educação e Culturas Afro- 
brasileiras por desejar aprofundar seus conhecimentos na área. Logo após participação no curso, realizou, em parceria com uma colega, um trabalho tentando abordar as relações étnicas a partir das religiões de matriz africana e foi rechaçada pela direção da escola e demais colegas que não compreenderam a proposta. A situação descrita pela professora revela a forma como a comunidade escolar intersecciona a vivência religiosa judaico-cristã e o contato com as culturas afrobrasileiras no fazer docente. As vivências de Ayo revelam assim como Santana (2016, p. 27), os "limites e desafios que uma sociedade com ensinamentos do colonizador branco, cristão e maniqueísta nos impunham durante tantos séculos". Por conseguinte, isso reflete negativamente nos avanços dessa temática, promovidos pela legislação vigente, no contexto escolar.

Zunduri se autodeclara negra e há 08 anos atua como professora da educação básica. Cursou duas graduações, uma especialização e mestrado. Participou de três formações no ODEERE. Seu interesse pelo curso de extensão foi o encantamento pela pós-graduação e desejo de melhor trabalhar a temática com seus alunos. Essa professora relata que após o curso passou a tomar consciência de alguns problemas presentes no cotidiano escolar e, para dar conta dessas questões, passou a utilizar como recurso metodológico a literatura infanto-juvenil, através dos mitos africanos, da oralidade, e das memórias dos alunos, pois "isso trouxe muitas vezes à tona questões em que eu pude discutir relações étnicas".

A participação no curso de Extensão em Educação e Culturas Afro-brasileiras, promovido pelo ODEERE, aproximou as professoras dos elementos simbólicos que trazem referência aos aspectos históricos dos povos negros, às relações estabelecidas a partir do pertencimento, ao sagrado e seus simbolismos, aos valores e concepções que regem a vida desses povos. Dessa maneira, conforme assinala Barth (2011), a consciência de pertencer a um grupo étnico possibilitou às professoras a articulação da base epistemológica do curso com suas próprias identidades.

Tomando o conjunto de colaboradoras da pesquisa, foi constatado que todas as professoras entrevistadas foram expostas às discussões de gênero e relações étnicas e à proposta de realizar um trabalho diferenciado na escola concernente às culturas afro-brasileiras. $O$ contato com tais discussões trouxe para as quatro professoras reações e aprendizados diferenciados. Nesse processo, cada professora, contando com os conhecimentos que já possuía e com suas vivências, 
apropriou-se de uma maneira e estabeleceu interações particulares com os temas e com o trabalho proposto pelo curso, atribuindo sentido às suas identidades profissionais. Assim, comprova-se o que Tardif (2014, p. 56 - 57) assevera ao afirmar que cada "identidade carrega as marcas de sua própria atividade, e uma boa parte de sua existência é caracterizada por sua atuação profissional".

$O$ contato com as categorias gênero e identidade étnica possibilitou as professoras reflexões acerca da posicionalidade ocupada enquanto mulheres negras, principalmente nos papéis desempenhados na família e mercado de trabalho. A intersecção do racismo e do sexismo passa a ser percebido por essas professoras e a lógica do patriarcado começa a ser questionada. À luz da formação, começam a perceber que a inserção da mulher negra no magistério configura-se como uma maneira de resistência, pois "ocupar profissionalmente esse espaço, que anteriormente era permitido só aos homens e brancos, significa muito mais que uma simples inserção profissional. É o rompimento com um dos vários estereótipos criados sobre o negro brasileiro" (GOMES, 1995, p. 115).

Partindo desse entendimento, a atuação de mulheres negras no magistério pode ser vista como o rompimento de ideias engendradas no imaginário social, no qual foi suplantada a imagem de incapacidade intelectual da mulher, especialmente a negra, para ocupar um espaço sob arestas de preceito, controle, raciocínio e ordem masculinas. Para essas profissionais, romper com esse viés, ao sair da esfera privada e inserir-se na pública, garantindo respeito a sua atividade profissional, trouxe um duplo desafio: o binômio de serem mulheres e negras, consideradas inferiores aos homens.

As identidades de gênero e étnica fundamentam-se na constituição simbólica de uma rede de representações e de significados, que as articulam com os demais elementos da cultura. Assim, os elementos simbólicos e identitários que marcam os saberes profissionais de mulheres-negras-professoras podem impactar diretamente na maneira como essas profissionais concebem e se posicionam, frente à realidade.

Os saberes profissionais de mulheres negras professoras são aqui entendidos como uma realidade cambiante permeada por identidades étnicas e de gênero. Partindo de tal compreensão, este estudo reporta-se aos diferentes agenciamentos simbólicos presentes nas tramas históricas da feminização do magistério, da construção da identidade étnica, tomando a autoafirmação como sua base fundadora dos saberes profissionais, por meio dos lugares assumidos pelas culturas 
produzidas em processos de interação e momentos históricos nos quais essas professoras estão inseridas. Com o intuito de melhor compreensão das categorias tratadas, organizam-se a seguir dois eixos de análise.

\subsection{REPRESENTAÇÕES DO SER MULHER NEGRA E TORNAR-SE PROFESSORA}

As histórias narradas pelas colaboradoras mostram que as identidades autoatribuídas demarcam as lutas diárias no processo de constituição do ser mulhernegra-professora no ato de identificar-se e diferenciar-se nas situações de interação e contato. Os processos identitários compõem-se de elementos historicizados, produzidos em realidades sócio-histórico-culturais em constante movimento, sendo que "a maneira como cada um se sente e se diz professor" (NÓVOA, 1997, p. 34) resulta das lutas e conflitos vivenciados em todo processo de desenvolvimento profissional.

As falas das professoras Ayo e Zunduri trazem discussões acerca do lugar da mulher negra na sociedade onde sofrem um duplo processo de invisibilidade em decorrência das representações sociais construídas sobre a mulher em geral e sobre as mulheres negras em particular (LOURO, 1997). Tudo isso se reflete em suas escolhas e identidades profissionais que, a partir de suas subjetividades, buscam estabelecer relações entre contexto, as questões de gênero, pertencimento étnico e saberes docentes que vêm conferindo-Ihes sentido na história pessoal e profissional. Isso fica visível no seguinte relato:

Enquanto negra e pobre a única opção que eu tive para conseguir uma profissão digna através dos estudos foi fazendo o magistério. Não foi bem uma escolha, foi imposição, pois aqui na região, mulher pobre e preta só tinha dois destinos: trabalhar em casa de família ou estudar para ser professora (PROFESSORA AYO).

O conteúdo dessa fala cruza com a historiografia brasileira ao mostrar que o magistério foi por anos a única profissão feminina respeitável e a única forma institucionalizada de emprego a qual cabia à mulher, promovendo ascensão social através da inserção profissional escolarizada. Remete ainda ao que Gomes (1995) trata por "sair do seu lugar". Ao tornar-se professora, Ayo sai do lugar predestinado às mulheres negras de sua região passando a ocupar uma posição constituída por um status social relacionado ao conhecimento. Pode-se inferir, à luz dos estudos de 
Saffioti (1976, p. 58), que para Ayo "ter um emprego significa participar da vida comum, ser capaz de construí-la, sair da natureza para fazer a cultura, sentir-se menos insegura na vida". Ao mesmo tempo, torna-se evidente que o magistério não foi uma escolha para essa professora, era a única opção que tinha para ter uma profissão reconhecida e fugir da invisibilidade feminina "produzida a partir de múltiplos discursos que caracterizaram a esfera do privado, o mundo doméstico, como o ‘verdadeiro' universo da mulher” (LOURO, 1997, p. 17).

As falas de Ayo conduzem um olhar acerca da interseccionalidade por enunciar uma sobreposição discriminatória entre classe social, gênero e raça. Essa limitação das chances profissionais imposta a Ayo coaduna com o pensamento de Kimberle Crenshaw (2002, p. 177) ao afirmar que "o racismo, o patriarcalismo, a opressão de classe e outros sistemas discriminatórios criam desigualdades básicas que estruturam as posições relativas de mulheres, raças, etnias, classes e outras".

A respeito do espaço privado como universo feminino, Zunduri relata: "eu nunca fui, assim, uma 'mulher dentro dos moldes antigos' para casar, porque eu não sei direito lidar com as tarefas domésticas". Ao se casar, se cobrava nesse aspecto e sofria ao dividir seu tempo entre as tarefas do lar, da carreira docente e da vida acadêmica. O imaginário social trouxe para sua vida esse desconforto, revelando que a mulher, ao alcançar o espaço público, carrega consigo uma subjetividade instituída a partir das representações sociais produzidas e reproduzidas como se fosse algo natural e verdadeiro.

A fala de Zunduri suscita reflexão acerca da construção da mulher e da professora, processo no qual ocorre e entrecruza com valores, práticas e comportamentos inscritos no "universo feminino". Atribuir à mulher o espaço privado ainda é comum em uma cultura patriarcal, onde os homens detêm a maior parcela dos privilégios. De acordo com os estudos de Louro (1997), atua na consciência social elementos constituintes de identidades trazendo para meninas, que se tornam mulheres, esposas, mães e professoras, formas de acomodação e resistência diante da divisão sexual dos papéis sociais. O caráter doméstico marca todo o trabalho feminino, atribuindo a organização do lar como responsabilidade da mulher.

No caso de Zunduri, esses elementos foram reforçados pela cobrança de familiares e interferiram na sua forma de pensar o ser mulher, durante muito tempo, por estarem nos "lugares de suas memórias" (NORA, 1993). Até que ao vivenciar as 
discussões de gênero no ODEERE, pôde restaurar o sentimento de domínio de sua própria vida fazendo emergir uma nova consciência.

O falar de si da professora, ativa os lugares de sua memória trazendo registros vividos e a partir das subjetividades recria lugares que trazem em si experiências e percepções. Esse processo de "metamorfose" vivido por Zunduri, apresenta-lhe uma nova consciência de si, livre das amarras patriarcais onde hoje ela se permite deixar de fazer o que antes considerava como obrigação para dedicar-se ao que realmente lhe interessa: os estudos.

A ruptura que Zunduri faz com os conceitos de gênero que permeavam suas vivências the ajudou a pensar melhor sua etnicidade. "Hoje o meu discurso me coloca em um lugar. O meu discurso me coloca ali, mulher-negra e isso me auxilia nas relações do dia a dia" (PROFESSORA ZUNDURI). Esses saberes foram "adquiridos através de certos processos de aprendizagem e de socialização que atravessam tanto a história de vida quanto a carreira" (TARDIF, 2014, p. 102 - 103). Pode-se dizer que sua identidade docente agregou questões teóricas às práticas, vivenciadas ao longo da vida pessoal e profissional.

Outro ponto a ser destacado, nas entrevistas, refere-se às questões culturais ligadas a gênero, que atravessam a educação e a formação das mulheresprofessoras. Vale aqui considerar o processo histórico da feminização do magistério no qual a mulher foi imbuída do papel educacional que vem historicamente sendo produzida. A transformação do magistério em trabalho de mulher foi designada através de um processo sócio-político-cultural desencadeado pela crescente presença das mulheres no trabalho docente e em decorrência do pensamento engendrado no imaginário social de que a "docência enquanto profissão feminina relaciona-se com os significados masculinos e femininos que permeiam a história de professores e professoras e suas práticas escolares" (VIANNA, 2002, p 92).

Dandara e Zulai, ao falarem acerca das questões de gênero, direcionam pensar a influência do processo da feminização do magistério em suas identidades profissionais, aproximando as construções sociais dos "papéis femininos" a exemplo da maternidade à profissão docente.

“Ensinar foi pra mim ação que sempre desenvolvi. O cuidado com o outro, a organização [...] eu fui orientada pra ser assim, pra ser organizada, pra ter cuidado, pra poder tomar conta de casa" (PROFESSORA DANDARA). O relato de Dandara vem reforçar a ideia que Louro (1997) e Vianna (2013) chamam de estereótipos da 
docência. Ao ingressar no magistério, acabam levando "algumas representações sobre mulher professora que circularam (e circulam) na sociedade e essas representações são capazes de dar sentido, ou numa expressão mais contundente, são capazes de contribuir para a produção dessas mulheres" (LOURO, 1997, p 8081).

Essas ideias criadas acerca do seu gênero são incorporadas na interpretação do ser professora, as quais Vianna (2013) denomina como significados femininos, a exemplo da virtude, amor, dedicação, cuidado e domesticidade. Tal marcação simbólica tem atribuído às mulheres e aos homens alguns atributos que, por não serem questionados, vão se estabelecendo como retrato da atividade docente.

Zulai traz elementos acerca de sua identidade profissional que reforçam esse imaginário social, ao relatar "a gente não deixa de ser também um pouquinho mãe, um pouquinho parente, até porque a criança já tem essa afinidade, né, conosco" (PROFESSORA ZULAI). Mais uma vez aparece a ação praticada no lar como representação profissional. Estas representações da docência como extensão da atividade doméstica passa a ideia da escola como um espaço feminino, contemplando os significados sociais e culturais do magistério e reforçando o binarismo dos significados de ser homem e de ser mulher (LOURO, 1997).

Nesse sentido, os relatos de Dandara e Zulai revelam que a mulher, ao alcançar o espaço público, nesse caso a carreira do magistério, carrega consigo uma subjetividade instituída a partir das representações sociais produzidas historicamente.

Outrossim, cabe considerar que as identidades são plurais e nem todas as mulheres-professoras acataram esse modelo de exercer a docência. $\mathrm{Na}$ trajetória profissional, muitas delas buscaram novos referenciais para realizar adaptações ou reinventar tais modelos, mostrando que há "diferentes representações de professoras e professores, nas quais alguns se reconhecem e às quais outros rejeitam e recusam" (LOURO, 1997, p. 83).

Os relatos oferecem a possibilidade de dialogar com Scott (1995, p. 89), ao enfocar que "o gênero, então, fornece um meio de decodificar o significado e de compreender as complexas conexões entre várias formas de interação humana". Dessa maneira, os sujeitos são construídos por meio das experiências e, na tentativa de construir suas identidades, um conjunto de relações se estabelecem e utiliza-se de elementos constitutivos das relações de gênero descritos pela autora. $O$ 
primeiro deles refere-se aos símbolos culturalmente disponíveis que evocam os estereótipos criados a partir da feminização do magistério, o segundo, aos conceitos normativos reforçadores da sociedade patriarcal e promotores da divisão sexual do trabalho, e por fim, refere-se a identidade subjetiva que possibilita a reelaboração do modelo dado, cultural e historicamente, de ser professora.

Como defende Scott (1995), esses elementos não surgem de maneira linear ou estática, mas em um constante diálogo travado com as próprias professoras, a partir de suas vivências, das relações estabelecidas com outras pessoas e da maneira como cada uma ressignifica esses referenciais identitários, durante a trajetória de vida. E ao buscar nas memórias das colaboradoras, relatos que descrevam como elas têm construído/vivenciado as concepções de gênero, nas diversas relações estabelecidas, enquanto mulheres-negras-professoras, percebese que os contextos históricos e culturais direcionam pensar suas identidades profissionais de acordo com o papel exercido nos variados momentos de suas vidas: filha, cuidadora dos irmãos, esposa, professora, cursista de formação continuada no ODEERE, entre outros.

O engendramento de gênero, vivenciado por essas professoras, durante a atuação em diferentes papéis sociais, produziu efeitos sobre elas, condicionando posturas, atitudes e comportamentos, influenciando as formas de expressão e manifestação profissional.

Diante do exposto, há de considerar as noções de gênero que aparecem nas narrativas e individualidades de cada professora, a relação estabelecida com o outro e o contexto sócio-histórico-cultural, pois como afirma Louro (2008, p. 18), gênero é uma construção dada "através de inúmeras aprendizagens e práticas, insinua-se nas mais distintas situações, é empreendida de modo explícito ou dissimulado por um conjunto inesgotável de instâncias sociais e culturais. É um processo minucioso, sutil, sempre inacabado".

\subsection{AFIRMAÇÃO ÉTNICA E SABERES PROFISSIONAIS}

Nas interações vivenciadas pelas professoras negras no ambiente escolar com pessoas não negras (colegas e alunos), com o conhecimento e com o currículo, pensados na lógica dos paradigmas eurocêntricos, são destacados traços étnicos, aos quais evidenciam diferenças indicando a condição de pertencimento, além da construção que cada uma faz de si mesma, através dos sistemas simbólicos 
culturais pelos quais são representadas. Assim, ao afirmar que são negras, o fazem como meio de diferenciação em relação à escola com a qual se defrontam.

E sob a perspectiva dos estudos de Barth (2011), pode-se inferir que as professoras indicaram em seus relatos que a autoafirmação foi possibilitada em vivências de atribuição (de pessoas para com elas) e de autoatribuição (delas em relação a elas próprias), em momentos e situações diversas, expressando distinções étnicas. Esse processo, segundo o autor, promove a transferência do olhar da constituição interna (ou cultural) dos grupos para as fronteiras que diferenciam e as mantêm.

O processo de reconhecimento e autoafirmação étnica se configuram como singular para cada professora. Desde a ideia de influência do Curso de Extensão em Educação e Culturas Afro-brasileiras na percepção e afirmação da identidade étnica, no caso da professora Zulai, até na necessidade expressada por Zunduri de estar constantemente afirmando e reafirmando seu pertencimento diante das fronteiras "rígidas" em relação às suas questões religiosas.

Para Zulai, sua participação no curso trouxe-lhe conhecimento para notar maior aproximação do seu modo de viver com a cultura afro-brasileira. Até então, considerava-se branca e os conteúdos trabalhados no curso trouxeram o "realce" de sua pertença étnica em meio a possíveis outras identidades (BARTH, 2011). Os traços étnicos destacados na interação social, propiciada pelo curso, revelaram características definidoras do grupo étnico com o qual Zulai se identificou e ampliou o índice e critério que a definia como branca: a cor da pele.

Essa etnicidade tem influenciado a atuação profissional de Zulai, pois segundo a mesma, a partir de então "as palavras são melhores, o respeito também", uma vez que o curso lhe trouxe embasamento teórico e prático para melhor compreender e mobilizar seus saberes docentes, projetando uma imagem positiva dos diferentes grupos étnicos.

Os relatos de Dandara trazem outros elementos para se pensar a identidade étnica, a exemplo do pensamento de Poutignat e Streiff-Fernart (2011) quando tratam da "origem comum" e "fronteiras étnicas". Durante toda a entrevista, essa professora reporta-se ao passado (memória ancestral) para distinguir seu pertencimento étnico das identidades coletivas. Por outro lado, Dandara é vista por seus alunos de maneira estereotipada, por conta dos os elementos simbólicos de sua cultura externados através das vestimentas, religiosidade e vocabulário típico. 
Esses sentem dificuldade em entender os sistemas simbólicos da cultura negra e atribuem ao modo de viver da professora significados depreciativos, tendo como suporte ideias eurocentradas que permanecem engendradas no imaginário social.

De acordo aos estudos de Poutignat e Streiff-Fernart (2011, p. 168), "o domínio do realce de uma identidade étnica é delimitado pelas múltiplas fontes dos estereótipos pelos quais os membros de uma sociedade definem as pessoas e situações". Isso torna-se vivível no relato da professora Dandara quando tem uma exodefinição atribuída por seus alunos, provindas do imaginário social que, ao hierarquizar as culturas, coloca o universo afro-brasileiro numa escala de inferioridade, principalmente no que tange às questões religiosas. Dessa maneira, a comunicação de sua identidade étnica parte da diferença anunciada através da autoconsciência de pertencer a um grupo étnico.

Essa situação também é compartilhada pela professora Zunduri. No encontro com o "outro", ela preserva os valores culturais marcados pelos elementos simbólicos de sua identidade étnica, no intuito de preservar suas raízes históricas. Relata que está sempre afirmando "eu sou negra, me reconheço como negra, estou sempre comunicando, contando esses preconceitos que sofri, que sofro por conta da religião, de outras coisas" (PROFESSORA ZUNDURI).

Essa fala traz à tona a ideia de que essas professoras vêm construindo suas identidades de mulheres negras a partir daquilo que assumiram e se identificaram durante toda história de vida. E em busca da autoafirmação, utilizam-se de vários artifícios para demarcarem o pertencimento étnico, ora mostrando que seus antepassados foram negros, ora utilizando-se da linguagem e dos sistemas simbólicos representativos da identificação étnica. Conforme Cunha (2009, p. 237), a linguagem é "um sistema simbólico que organiza sua percepção do mundo" e, ainda, constitui-se "um diferenciador por excelência" diante das situações de contato em que as diferenças culturais são percebidas como importantes e socialmente relevantes.

Considerando as experiências com as relações étnicas vivenciados pelas quatro professoras negras, o reconhecimento da subjetividade tem atribuído sentido na constituição das identidades profissionais, por ser um processo cultural no qual são inclusos valores, sentidos, opções e significados no contexto em que se encontram. 


\section{ALGUMAS CONSIDERAÇÕES}

Os relatos das colaboradoras desse estudo apresentam elementos para pensar os sentidos atribuídos ao curso de formação continuada oferecido pelo ODEERE na percepção, reconhecimento e/ou embasamento teórico para a identidade de gênero e afirmação do pertencimento étnico, assim como a mobilização de saberes profissionais para lidarem com questões desta natureza em suas práxis. Tal mobilização retrata o resultado de construções ancoradas em identidades plurais, múltiplas, incompletas e não fixas, que por vezes são omitidas, vivenciadas, assumidas e/ou transformadas. Isso ocorre porque os saberes profissionais integram diferentes saberes oriundos da formação inicial e continuada, bem como das experiências sociais.

Nesse ínterim, o Curso de Extensão em Educação e Culturas Afro-brasileiras tem produzido saberes na prática social fazendo a mediação para a aproximação das questões de gênero e pertencimento étnico das professoras, em suas práticas profissionais. Os relatos das colaboradoras conduzem pensar que a aprendizagem vivenciada no espaço do ODEERE tem privilegiado o desenvolvimento das dimensões objetivas e subjetivas do ser, produzindo saberes que são mobilizados, utilizados e produzidos no âmbito das tarefas cotidianas.

Nessa perspectiva, quando professoras participam de uma formação continuada que as convida a reverem suas percepções de gênero e pertencimento étnico, muitas coisas entram em jogo: religião, vivência pessoal e profissional, visão de educação, em meio a outras. A análise realizada revelou que o processo de construção identitária de mulheres-negras-professoras se diferenciam nas particularidades de suas histórias, de suas posturas diante do mundo, de seus olhares para os meios que as constituem e constituíram devido suas condições de mulheres, de negras e de professoras. Acontece em diferentes momentos e interações sociais, e isso reverbera na mobilização de saberes oriundos de diferentes fontes e condicionados pela trajetória de vida de cada uma delas. 


\title{
THE BLACK WOMAN TEACHER AND HER PLACES OF BELONGING
}

\begin{abstract}
:
This article is the result of an investigation carried out with a group of black-female teachers of a continuing education program promoted by the Ethnic Relations and Education Organization (ODEERE) of the State University of Southwest Bahia (UESB). It focuses on the construction of professional knowledge, giving priority to gender and ethnic identities. The purpose of this study was to investigate how black teachers from ODEERE's Afro-Brazilian Education and Cultures Course have articulated gender and ethnicity issues in their professional knowledge, seeking to understand the pathways and dilemmas of this process. In this sense, the categories of gender, ethnic identity and professional knowledge were analyzed. This is a qualitative empirical research, anchored in Oral History. The findings present elements to think about the meanings attributed to the continuing education program about the perception, recognition and / or theoretical basis for gender identity and affirmation of ethnic belonging, as well as the mobilization of professional knowledge to deal with issues of this nature in their praxis.
\end{abstract}

Keywords: Black Teachers. Gender. Ethnic Identity. Professional Knowledge.

\section{LA MUJER NEGRA PROFESORA Y SUS LUGARES DE PERTENECIMIENTO}

\section{Resumen:}

Este artículo es el resultado de una investigación llevada a cabo con un grupo de mujeres negras profesoras de un programa de educación continua, promovido por el Órgano de Educación y Relaciones Étnicas (ODEERE), de la Universidad del Sudoeste del Estado de Bahía (UESB). Se centra en la construcción de sabberes profesionales, privilegiando las identidades de género y étnicas. Por lo tanto, este estudio tuvo como objetivo investigar cómo las profesoras negras graduadas del Curso de Extensión en Educación y Cultura Afro-Brasileña del ODEERE han articulado las cuestiones de género y origen étnico de sus conocimientos profesionales, tratando de comprender las vías y los dilemas de este proceso. En este sentido, se analizó las categorías de género, identidad étnica y conocimientos profesionales. Se trata de una investigación empírica, de naturaleza cualitativa, anclado en la historia oral. Los resultados tienen elementos para pensar acerca de los significados atribuidos al curso de educación continua en la percepción, reconocimiento y/o la base teórica de la identidad de género y la afirmación de la pertenencia étnica, así como la movilización de los conocimientos profesionales para hacer frente a estas cuestiones en su práctica.

Palabras clave: Profesoras Negras. Género. Identidad Étnica. Saberes Profesionales. 


\section{REFERÊNCIAS}

BARTH, Fredrik. Os grupos étnicos e suas fronteiras. In: POUTIGNAT, Philippe; STREIFF_FENART, Jocelyne. Teorias da Etnicidade. Seguido de Grupos Étnicos e suas fronteiras de Fredrik Barth. Tradução de Elcio Fernandes. 2 ed. - São Paulo: Ed. Unesp, 2011.

CRENSHAW, K. Documento para o encontro de especialistas em aspectos da discriminação racial relativos ao gênero. Estudos Feministas, Florianópolis, v. 10, n. 1, p. 171-188, jan. 2002.

CUNHA, Manuela Carneiro. Cultura com aspas e outros ensaios. São Paulo: Cosac Naify, 2009.

GOMES, Nilma Lino. A mulher negra que vi de perto: o processo de construção da identidade racial de professoras negras. Belo Horizonte: Mazza Edições, 1995.

LARAIA, Roque de Barros. Cultura: um conceito antropológico. 11 ed. Rio de Janeiro: Zahar Editor, 1996.

LOURO, Guacira Lopes. Gênero, sexualidade e educação. Petrópolis, RJ Uma perspectiva pós-estruturalista: Vozes, 1997.

LOURO, Guacira Lopes. Gênero e sexualidade: pedagogias contemporâneas. PróPosições, v. 19, n. 2 (56) - maio/ago. 2008.

MEIHY, J. C. S. B.; HOLANDA, F. História oral: como fazer, como pensar. São Paulo: Contexto, 2013.

NORA, Pierre. Entre memória e história: a problemática dos lugares. In: Projeto História: São Paulo: PUC, nº 10. Dez. 1993.

NOVOA, Antonio. Formação de professores e profissão docente. In: NÓVOA, António. Os professores e sua formação. Lisboa: Dom Quixote/IIE, 1997.

POUTIGNAT, Philippe; STREIFF_FENART, Jocelyne. Teorias da Etnicidade. Seguido de Grupos Étnicos e suas fronteiras de Fredrik Barth. Tradução de Elcio Fernandes. 2 ed. - São Paulo: Ed. Unesp, 2011.

SAFFIOTI, Heleieth lara Bongiovani. A mulher na sociedade de classes: mito e realidade. Petrópolis: Vozes, 1976. 
SANTANA, Marise de. ODEERE: formação docente, linguagens visuais e legado africano no sudoeste baiano. Vitória da Conquista: Edições UESB, 2014.

SCOTT, Joan. Gênero: uma categoria útil de análise histórica. Educação e realidade. Porto Alegre: v. 16, n. 2, julho/dezembro de 1995.

SILVA, Tomaz Tadeu da (Org.). Identidade e diferença: a perspectiva dos estudos culturais. Petrópolis: Vozes, 2014.

SOUZA, Neusa Santos. Tornar-se negro: as vicissitudes da identidade do negro brasileiro em ascensão social. Rio de Janeiro: Edições Graal, 1983.

TARDIF, Maurice. Saberes docentes e formação profissional. Petrópolis: Vozes, 2014.

VIANNA, Cláudia Pereira. O sexo e o gênero da docência. Cadernos Pagu, Campinas, n. 17-18, 2001-2002. 